University of Nebraska - Lincoln

DigitalCommons@University of Nebraska - Lincoln

Faculty Publications, Department of Psychology

Psychology, Department of

$11-1999$

\title{
A Longitudinal Examination of the Consequences of Sexual Victimization for Rural Young Adult Women
}

Janine Zweig

Urban Institute, Washington, DC

Lisa J. Crockett

University of Nebraska-Lincoln, ecrockett1@unl.edu

Aline Sayer

Pennsylvania State University

Judith Vicary

Robert Wood Johnson Foundation, Princeton, NJ

Follow this and additional works at: https://digitalcommons.unl.edu/psychfacpub

Part of the Psychiatry and Psychology Commons

Zweig, Janine; Crockett, Lisa J.; Sayer, Aline; and Vicary, Judith, "A Longitudinal Examination of the Consequences of Sexual Victimization for Rural Young Adult Women" (1999). Faculty Publications, Department of Psychology. 350.

https://digitalcommons.unl.edu/psychfacpub/350

This Article is brought to you for free and open access by the Psychology, Department of at DigitalCommons@University of Nebraska - Lincoln. It has been accepted for inclusion in Faculty Publications, Department of Psychology by an authorized administrator of DigitalCommons@University of Nebraska - Lincoln. 


\title{
A Longitudinal Examination of the Consequences of Sexual Victimization for Rural Young Adult Women
}

\author{
Janine M. Zweig \\ The Urban Institute, Washington, DC \\ Lisa J. Crockett \\ University of Nebraska \\ Aline Sayer \\ The Pennsylvania State University \\ Judith R. Vicary \\ The Pennsylvania State University \\ Robert Wood Johnson Foundation, Princeton, NJ
}

This longitudinal study examined the consequences of sexual victimization in a sample of 237 young adult women from a rural community. Of the total sample, 71 (30\%) reported experiencing some type of unwanted sex. Multiple regression was used to examine the effects on psychosocial adjustment of unwanted sex that occurred through nonviolent coercion and violent coercion, respectively, controlling for prior psychological adjustment. Results indicated that women who reported physically violent sexual coercion exhibited poorer psychological and social/relational adjustment than either nonvictimized women or women who had experienced nonviolent forms of sexual coercion. Additionally, nonviolent sexual coercion was associated with higher sexual depression, compared with nonvictimized status. A second set of regressions compared adjustment outcomes for women reporting four types of sexual coercion: (a) internal psychological pressure, (b) substance-related coercion, (c) external psychological manipulation, and (d) violent coercion. Controlling for earlier psychological adjustment, women who had unwanted sex because of either violent coercion or external psychological manipulation reported lower levels of psychological adjustment than women who had unwanted sex because of internal psychological pressure or substance-related coercion.

Sexual victimization is a pervasive problem for women today. According to the National Crime Victimization Study, in the United States women ages 12 years and older report 500,000 rapes and sexual assaults annually (Bachman \& Saltzman, 1995). The psychosocial consequences of sexually victimizing experiences merit particular attention, as it is widely believed that sexual victimization has implications for how a woman feels about herself and her life, and how she behaves subsequent to victimization. Numerous studies have demonstrated associations between victimization and psychological, social, and relational adjustment outcomes. However, most prior research on this topic has been limited by one of three shortcomings.

First, although some studies have examined sexual victimization longitudinally, most have not controlled for

This research was supported by a grant from the Office of Pregnancy Prevention Programs to Dr. Judith R. Vicary (grant \#000933-01) and a grant from the National Institute on Alcoholism and Alcohol Abuse to Dr. Lisa J. Crockett (grant \#1 R01 AA096787). Results are partially based on a dissertation conducted by the first author and were presented at the biennial meeting of the Society for Research on Adolescence, February 26 - March 1, 1998, San Diego, CA. The authors would like to thank Drs. Elizabeth Susman and Michael Johnson for their contributions to the present study, and all the members of the research project who collected, coded, and entered data through the years.

Address correspondence to Janine M. Zweig, The Urban Institute, $2100 \mathrm{M}$ St., NW, Washington, DC 20037; e-mail: jzweig@ui.urban.org. adjustment prior to sexual victimization experiences and thus cannot disentangle the effects of sexual victimization from effects of prior psychological adjustment. In many cases, controlling for adjustment prior to victimization was not possible because the sample was recruited and followed only after the women were victimized (Murphy et al., 1988; Siegel, Golding, Stein, Burnam, \& Sorenson, 1990). Second, although some studies have identified different types of sexual victimization, few studies have examined the differential effects of these distinct coercive experiences on women's adjustment. Third, few studies examine the impact of sexual victimization within community samples of women, instead of college or clinical samples (George, Winfield, \& Blazer, 1992; Zweig, Barber, \& Eccles, 1997). The current study addressed these three limitations by utilizing a community sample of rural women who had been previously surveyed as adolescents. As adults, the women reported diverse types of victimization, making it possible to examine the consequences of different types of sexually victimizing experiences, while controlling for adjustment prior to victimization. Based on the prior literature on sexual victimization, three types of adjustment outcomes were considered: (a) mood, (b) self-perceptions, and (c) social/relational adjustment.

\section{Mood Outcomes of Sexual Victimization}

Women who have been sexually victimized often report 
higher levels of depression (Miller, Monson, \& Norton, 1995; Muehlenhard, Goggins, Jones, \& Satterfield, 1991; Siegel et al., 1990; Zweig et al., 1997). For instance, adolescent females who reported unwanted sexual activity were more likely than other females to exhibit symptoms of depression (Erickson \& Rapkin, 1991). For adult women, Mackey et al. (1992) examined reports of depressive symptomology from a sample of 69 rape victims. Of those women, $11 \%$ reported severe depression, $29 \%$ reported moderate to severe depression, $21 \%$ reported mild to moderate depression, and $40 \%$ were minimally or not depressed.

Feelings of anger and hostility are also greater among women who report sexual victimization. Adolescent females who had unwanted sexual experiences reported difficulty controlling their anger (Erickson \& Rapkin, 1991), while young adult women who were sexually coerced reported greater levels of anger than women who were not coerced (Zweig et al., 1997). It may also be common for women to feel anger toward the perpetrator of the sexual coercion (Muehlenhard et al., 1991).

\section{Self-Perception Outcomes of Sexual Victimization}

Sexual victimization has been linked to lower self-esteem, although this link has not been shown consistently. In a number of studies, women who reported victimization also reported lower self-esteem than women without a history of victimization (Jehu \& Gazan, 1983; Murphy et al., 1988; Resick, 1993; Zweig et al., 1997). However, longitudinal studies indicate that the negative effects on selfesteem tend to dissipate over time (Murphy et al., 1988). Moreover, some studies find no relationship between sexual victimization experience and reports of lower selfesteem (Miller et al., 1995). Thus, self-esteem may be affected by sexually victimizing experiences, but the strength and persistence of this effect is unclear.

Sexual victimization may also be related to a woman's body image. Although this relationship has not been examined directly, weight and eating problems have been linked to sexual victimization experiences. Erickson and Rapkin (1991) reported that adolescent females who experienced unwanted sexual activity were more likely to report weight problems than those who did not have these experiences. Kearney-Cooke (1988) reported that a high percentage of bulimic women have been sexually abused. She suggested that sexually victimizing experiences and the powerlessness that is often felt by women who experience victimization may be important contributing factors to the development of eating disorders. Because of this, it is plausible that some body image disturbances may be connected to sexual abuse episodes (Kearney-Cooke, 1988).

\section{Social/Relational Adjustment Outcomes of Sexual Victimization}

Social and relational adjustment is another area in which sexually victimized women display problems (Resick, 1993). Zweig et al. (1997) reported that women who had experienced sexual coercion were more likely to report social isolation than women who had not been victimized. Moreover, some women have reported a fear of intimate relationships or an avoidance of relationships in response to a sexually abusive experience (Jehu \& Gazan, 1983). Finally, women who have been sexually victimized sometimes report problems with their romantic relationships, particularly if the perpetrator of the victimization was a romantic partner. Christopher (1988) reported that being pressured into sexual activity in the early stages of a relationship was especially likely to result in decreased quality of that relationship.

Additionally, sexual victimization seems to affect women's ability to have healthy and satisfying sexual relationships (Kilpatrick, Best, Saunders \& Veronen, 1988; Resick, 1993). Some studies show that women who have been sexually victimized reported lower levels of sexual satisfaction and pleasure than women who have not been victimized (Siegel et al., 1990; Zweig, 1995). Many factors may relate to this decrease in sexual satisfaction. Some women report a general decrease in sexual interest following sexual assaults (Siegel et al., 1990). Also, a rape experience may lead a woman to associate sex with violence, resulting in "flashback" experiences during voluntary sexual encounters (Wiehe \& Richards, 1995).

\section{Outcomes Related to Different Types of Sexually Victimizing Experiences}

There is some evidence that the type of victimization a woman experiences is related to her reaction to the experience. However, only a small number of studies have compared the effects of different kinds of victimization experiences, and, like many of the studies presented previously, most have relied on cross-sectional data. Findings have been mixed.

Some studies indicate that women who are coerced by psychological means have worse outcomes than those who are physically coerced. Mynatt and Allgeier (1990) found that women who were coerced into sexual activity by psychological manipulation reported more severe adjustment problems than women who were coerced by physical means. Similarly, Zweig et al. (1997) found that women who were pressured into having sex reported more depressed mood and more social anxiety than either women who reported violent coercion or women who reported no coercion. Using the same categories of coercion, Zweig (1995) found a similar pattern, with women who were pressured into sex reporting lower levels of sexual satisfaction than women who were violently coerced or women who were not coerced.

Other researchers have found the opposite pattern of results. Siegel et al. (1990) reported that participants who had been physically threatened during their sexual assault were more likely to report sexual problems, fear, and depression than those who were pressured by persuasion. Thus, the evidence supports the idea that physical and psychological coercion elicit varying degrees of problems, but 
the evidence is mixed concerning which type of experience is most debilitating.

\section{The Present Study}

The current study sought to extend the prior literature in several ways. First, we investigated the psychological effects of sexual victimization in longitudinal analyses that included controls for earlier psychological adjustment. Based on prior findings, we hypothesized that both violent and nonviolent sexual coercion would be associated with poorer psychological and social/relational adjustment compared to no victimization. Second, we identified four distinct subtypes of coerced sex and compared adjustment outcomes for women who had experienced different subtypes. Our concern in these latter analyses was whether distinct types of sexual coercion differentially affected women's subsequent adjustment.

We employed a broad definition of sexual victimization: Any instance of unwanted intercourse was regarded as an instance of coercion and sexual victimization. This approach is consonant with many previous studies (e.g., Erickson \& Rapkin, 1991; Himelein, 1995; Himelein, Vogel, \& Wachowiak, 1994; Koss, Gidycz, \& Wisniewski, 1987; Muehlenhard \& Cook, 1988), but other researchers argue that some instances of unwanted intercourse are consensual and should not count as victimization (O'Sullivan \& Allgeier, 1998). ${ }^{1}$ Our goal was not to resolve this definitional issue but rather to examine the effects of different types of unwanted sex empirically in order to determine which kinds of experiences are most debilitating for women.

Analyses focused on sexual victimization experiences that occurred during adolescence and young adulthood. This period of the lifespan was selected because victimization is most likely to occur during this age range. According to the National Crime Statistics, women ages 16 to 24 are 3 times more likely than women of other ages to be raped (Harlow, 1991). Similar to the approach taken in the National Health and Social Life Survey, which differentiated between prepubertal and postpubertal victimization (Laumann, Gagnon, Michael, \& Michaels, 1994), subjects who experienced victimization prior to age 12 were excluded from analysis.

\section{METHOD}

\section{Design}

The present study was part of a larger ongoing project examining developmental issues for rural youth during adolescence and young adulthood. The design of the original study was a longitudinal cohort-sequential design (Baltes, Reese, \& Nesselroade, 1977) where three cohorts (the seventh, eighth, and ninth grade classes in 1985) from one rural school district were followed for the past 14 years. Data collection began in junior high and occurred

${ }^{1}$ We thank an anonymous reviewer for bringing this concern to our attention. annually throughout high school; periodic follow-ups were conducted during the post high school years, for a total of eight waves of data.

\section{Procedure}

During the fall of each school year, students were divided by gender for one class period, and trained project members administered written surveys (Crockett, Bingham, Chopak, \& Vicary, 1996; Vicary, Klingamen \& Harkness, 1995). Confidentiality was emphasized. Adolescents whose parents did not allow them to participate were excluded from data collection. Incentives for participation were offered through raffle items, such as tickets to football games.

In 1995, participants were contacted again for an eighth wave of data collection. Members of all three cohorts were mailed a survey assessing educational experiences, work experiences, romantic partnerships, parenting, psychological adjustment, substance use, and sexual experiences.

\section{SAMPLE}

The original sample included junior high students from one rural public school district in the eastern United States. The school district included two junior high schools, each with grades seven, eight, and nine (Crockett et al., 1996). All participants were Caucasian and living in a geographically isolated rural area. This area was considered to be economically and educationally deprived when data collection began in 1985 (Vicary, 1991). Of the eligible female students in 1985, 96\% participated in the study (Vicary et al., 1995).

The analyses reported in this paper are restricted to women who participated in both Survey 8 and in the adolescent portion of the study at Grade 9. In total, 249 women participated in Survey 8, representing $71 \%$ of the female sample. Seven women were excluded from analysis because they reported childhood sexual abuse (victimization before age 12). ${ }^{2}$ In addition, five women were excluded from analysis because of inconsistent reports of sexual victimization that could not be resolved; these women were excluded to avoid misclassification. Therefore, the sample for this study included 237 women ( $68 \%$ of the total female sample). ${ }^{3}$

In order to test for bias related to differential attrition, the adolescent data for individuals who participated in Survey $8(n=237)$ were compared to those who did not participate in Survey $8(n=92)$. A series of $t$-tests was conducted to compare mean differences on several

\footnotetext{
${ }^{2}$ Women were asked if they were ever forced to have sex. If they responded that they had, they then answered the age at which the first forced sexual experience occurred. Women who reported a forced experience before age 12 were not included in the sample, because the current study was limited in scope to adolescent and young adult victimization.

${ }^{3}$ If data for Grade 9 adjustment variables were not available for women who reported unwanted sexual experiences at young adulthood, then these data were imputed. In total, data were imputed for Grade 9 adjustment variables for 9 victimized women. If women participated in the study during Grade 7,8, or 10, then their own data from one of these grades were substituted for the missing Grade 9 scores. Four women who reported sexual victimization did not have data from any grade listed previously, and were therefore excluded from regression models controlling for adolescent adjustment.
} 
Grade 9 variables, including frequency of drunkenness, frequency of sexual intercourse, antisocial behavior, gender role attitudes, emotional tone, self-esteem, school grades, quality of peer relationships, quality of family relationships, and mother's education. Based on these tests, the attrited group had a significantly higher frequency of drunkenness $(M=2.17$ vs. $M=1.81), t(307)=2.66, p<.05$, and sexual intercourse $(M=1.91$ vs. $M=1.59), t(306)=2.35, p<.05$, at Grade 9 than the group who participated in Survey 8, along with significantly lower school grades $(M=5.90$ vs. $M=6.25), t(304)=-2.06, p<.05$. These differences suggest that the women who participated at Survey 8 were somewhat better adjusted than the attrited group.

The women ranged in age from 12 to 16 years $(M=14)$ at Grade 9 and from 21 to 26 years $(M=23)$ at Survey 8 . Seventy-nine percent of the women lived in rural areas at the time of follow-up; the remaining women lived in suburban areas (7\%), urban areas (12\%), or on military bases (1\%). Level of educational attainment varied: $6 \%$ of the women had not finished high school, $6 \%$ had completed their GED, 27\% had graduated from high school, $12 \%$ had received technical training after high school, $20 \%$ had completed some college, $26 \%$ had graduated from college, and $3 \%$ had received graduate or professional training.

At Survey 8, $41 \%$ of the women were married, $14 \%$ were engaged, $4 \%$ were divorced/separated, $40 \%$ were single, and $1 \%$ were remarried. Among the 94 single women who were not engaged, $16 \%$ were living with their partners, $22 \%$ were in steady, committed relationships, and $19 \%$ were in casual dating relationships. Almost all the women in the sample identified themselves as heterosexual $(99 \%)$. One woman identified herself as bisexual and 2 reported they were uncertain about their sexual orientation. Ninety-five percent $(n=222)$ of the women reported having experienced sexual intercourse.

\section{MEASURES}

Measures used in the current study are listed below. Selfesteem and emotional tone were measured in Grade 9 and in young adulthood. All other measures were assessed only in young adulthood. Scale scores were computed by averaging item scores for that measure. A scale score was only generated for individuals who answered at least $75 \%$ of the items in that scale. Higher scale scores reflect higher levels of the latent construct of interest.

For established measures, scale validity was reported by the scale author. For measures created or adapted for the current study, convergent and discriminant validity coefficients were estimated by correlating the scale score of interest with items or scales in the survey that assessed similar or opposing constructs. For scale reliability, estimates of internal consistency (i.e., Cronbach's alpha) were computed using the present sample.

\section{Mood}

Emotional tone. Adolescents' emotional well-being was assessed with the Emotional Tone subscale of the Self-
Image Questionnaire for Young Adolescents (SIQYA; Petersen, Schulenberg, Abramowitz, Offer, \& Jarcho, 1984). This 11-item measure assesses positive mood (happiness) and negative mood (anxiety and depression). An example item is "Most of the time I am happy." The response scale is a 6-point Likert-type scale ranging from $1=$ Very strongly agree to $6=$ Very strongly disagree . Responses are averaged so that higher scores indicate more positive mood. Construct validity was estimated through factor analysis and through correlations with other self-image scales (Petersen et al., 1984). For the present sample, Cronbach's alpha was .87 for Grade 9 females and .91 for the young adult women.

Depression. The 6-item Kandel Depression Inventory assessed how much respondents were bothered by symptoms of depression over the past year (Kandel \& Davies, 1986). An example item is "Feeling unhappy, sad, or depressed." Responses ranged from $1=$ Much to $3=$ Not at all. Kandel and Davies (1986) reported evidence of scale validity and adequate test-retest reliability. Cronbach's alpha was .78 for the young adult women in the present sample.

Anger. The measure of anger was based on scales assessing anger and hostility developed by Derogatis and Melisaratos (1983) and McCrae and Costa (1989). An example of the 8 items is "I am easily annoyed or irritated." Responses ranged from $1=$ Very strongly agree to $6=$ Very strongly disagree. To examine construct validity, this scale was correlated with conflict in romantic relationships: $r=.37$ for verbal conflict and $r=.36$ for physical conflict. Cronbach's alpha was .84 for the young adult women.

\section{Self-Perceptions}

Self-esteem. The 10-item Rosenberg Self-Esteem Inventory was used to measure self-esteem (Rosenberg, 1965). An example item is "I wish I could have more respect for myself." The response scale ranged from 1 = Strongly agree to $4=$ Strongly disagree. Construct validity was examined by Rosenberg (1965) and found to be acceptable. Cronbach's alpha was .86 for Grade 9 females and .91 for the young adult women.

Body image. Body image was assessed using a subscale of the SIQYA (Petersen et al., 1984). This scale includes 8 items assessing how participants' perceive their bodies. An example is "Most of the time I am happy with the way I look." Responses ranged from $1=$ Very strongly agree to 6 $=$ Very strongly disagree. To examine validity, this scale was correlated with Rosenberg self-esteem scores, $r=.56$. Cronbach's alpha was .80 for the young adult women.

\section{Social/Relational Adjustment}

Assertiveness. The dating and assertion measure used in this survey was adapted from a scale designed by Levenson and Gottman (1978) to assess social competence. Five items were used from the original scale and three additional items were included. Responses ranged 
from $1=$ Never to $4=$ Almost always. The assertiveness subscale contained four items, such as how often participants can "say 'no' when you feel like it." To examine validity, assertiveness was correlated with self-esteem, $r=$ .50. Cronbach's alpha was .77 for the young adult women.

Intimacy competence. Intimacy competence was also assessed using the dating and assertion measure adapted from Levenson and Gottman (1978). The subscale consisted of three items; for example, how often the respondent can "accurately sense how a member of the opposite sex feels about you." To examine validity, this scale was correlated with the item "I really don't know how to make a serious relationship work," $\mathrm{r}=-.46$, and with the item "I am sure that I can have a satisfying intimate relationship," $r=$ 47. Cronbach's alpha was .81 for the young adult women.

Sexual esteem. Sexual esteem was assessed using three items from a subscale created by Snell and Papini (1989). An example item is "I am a good sexual partner." Responses were recorded on a 7-point scale ranging from 1 $=$ Strongly disagree to $7=$ Strongly agree. To examine validity, sexual esteem was correlated with Rosenberg selfesteem scores, $r=.45$. Cronbach's alpha was .88 for the young adult women.

Sexual depression. Sexual depression was assessed using two items from another subscale created by Snell and Papini (1989). An example item is "I am disappointed about the quality of my sex life." Responses were recorded on a 7-point scale ranging from $1=$ Strongly disagree to $7=$ Strongly agree. . To examine validity, sexual depression was correlated with Kandel depression scores, $\mathrm{r}=.34$. Cronbach's alpha was .70 for the young adult women.

Current romantic relationship quality. Relationship quality was assessed by a series of questions asking about positive affect in relationships. Some of these items were adapted from The Relationship Questionnaire by Braiker and Kelley (1979) and some were developed by project staff. An example of these items is "To what extent do you love your partner at this stage?" Responses ranged from $1=$ Not at all to $7=$ Very. Anchors varied with the specific quality being asked. To examine validity, this scale was correlated with the Dyadic Cohesion Scale (Spanier, 1976), $r=.62$. Cronbach's alpha was .92 for the young adult women.

\section{Sexual Victimization}

For the present study, measures of sexual victimization focused on intercourse. The type of intercourse was not specified (i.e., vaginal intercourse, oral intercourse, or anal intercourse). The intent was to include women who had experienced victimization other than through vaginal intercourse, but to exclude experiences such as forced kissing or forced sexual exposure.

Unwanted sex. To identify unwanted sexual experiences, participants were asked, "Have you ever had sexual intercourse with someone when you didn't want to?" If participants answered yes, they answered questions regarding the type of sexual victimization they had experi- enced. The sexual experience was intentionally not called rape or sexual assault, because some women may not be willing or able to label their experience in those terms (Koss, 1985). Additionally, Koss (1993) encouraged researchers to use behaviorally focused questions when studying victimization in order to increase a woman's recall of an event or willingness to report it. Women were also not asked if they had consented to the unwanted experience. Because the focus of this study was on the consequences of unwanted sexual experiences, the issue of consent was not central. A woman may "consent" under pressure, but still feel violated or compromised by the experience. Thus, all unwanted experiences were included even though some of these experiences could have been consensual (O’Sullivan \& Allgeier, 1998).

Types of sexual coercion. Respondents were asked whether they had ever had unwanted sex for 11 specific reasons (see Appendix A). They were instructed to check all the reasons that applied to them. This measure was adapted from two existing measures developed by Muehlenhard and Cook (1988) and Koss and Oros (1982).

Women were divided into four categories based on the most severe type of sexual coercion experienced. ${ }^{4}$ In order of increasing severity, these included: internal psychological pressure (items 10 and 11-e.g., "You felt obligated"), substance-related coercion (items 1, 2, and 3-e.g., "You were so drunk or stoned that you were unaware of what was going on"), external psychological manipulation (items 8 and 9-e.g., "The other person threatened to end the relationship"), and threat or actual use of violence by the perpetrator (items 4, 5, 6, and 7-"The other person used physical violence [for instance, slapping, hitting]"). For example, a woman who reported both substance-related coercion and external psychological manipulation was classified into the external psychological manipulation category. Some may argue that internal psychological pressure does not represent a form of sexual victimization given the large number of individuals who have sex out of a sense of obligation or in order to please the other person (O'Sullivan \& Allgeier, 1998). This category was included in the present analysis because, regardless of the circumstances leading up to the event, women identified these events as unwanted sexual experiences. As stated earlier, one goal of this study was to determine how different unwanted experiences impact psychosocial adjustment.

\section{RESULTS}

Seventy-one women $(30.0 \%)$ reported having an experience of sexual victimization. Using the four categories described previously, $25(35.2 \%)$ reported internal

\footnotetext{
${ }^{4}$ To check the validity of the specified hierarchy of severity, these results were compared to those based on an alternative ordering that ranged from internal psychological pressure to external psychological manipulation to substance-related coercion and finally to violent coercion. The results were almost identical to those reported here: Both sets of analyses indicated that external psychological manipulation and violent coercion are associated with poorer outcomes than internal psychological pressure and substance-related coercion.
} 
Table 1. Correlations Between Young Adult Outcome Variables

\begin{tabular}{|c|c|c|c|c|c|c|c|c|c|c|}
\hline & $\begin{array}{c}\text { Self- } \\
\text { esteem }\end{array}$ & $\begin{array}{l}\text { Emotional } \\
\text { tone }\end{array}$ & Depression & $\begin{array}{l}\text { Sexual } \\
\text { esteem }\end{array}$ & $\begin{array}{c}\text { Sexual } \\
\text { depression }\end{array}$ & $\begin{array}{l}\text { Body } \\
\text { image }\end{array}$ & Anger & Assertive & $\begin{array}{c}\text { Intimacy } \\
\text { competence }\end{array}$ & $\begin{array}{c}\text { Quality of } \\
\text { romantic rels }\end{array}$ \\
\hline Self-esteem & 1.00 & $.67 *$ & $-.55 *$ & $.45^{*}$ & $-.33 *$ & $.56^{*}$ & $-.49 *$ & $.50 *$ & $.31 *$ & $.23^{*}$ \\
\hline Emotional tone & & 1.00 & $-.56 *$ & $.37 *$ & $-.31 *$ & $.60 *$ & $-.65^{*}$ & $.40^{*}$ & $.19 *$ & $.22 *$ \\
\hline Depression & & & 1.00 & $-.33^{*}$ & $.34 *$ & $-.39 *$ & $.48^{*}$ & $-.34 *$ & $-.13 *$ & $-.17 *$ \\
\hline Sexual esteem & & & & 1.00 & $-.45^{*}$ & $.39 *$ & $-.34 *$ & $.41 *$ & $.37 *$ & $.33^{*}$ \\
\hline Sexual depression & & & & & 1.00 & $-.28 *$ & $.30 *$ & $-.18 *$ & $-.18 *$ & $-.27 *$ \\
\hline Body Image & & & & & & 1.00 & $-.44 *$ & $.31 *$ & $.16^{*}$ & .10 \\
\hline Anger & & & & & & & 1.00 & $-.29 *$ & -.13 & $-.26 *$ \\
\hline Assertiveness & & & & & & & & 1.00 & $.37 *$ & $.20^{*}$ \\
\hline Intimacy competence & & & & & & & & & 1.00 & $.48^{*}$ \\
\hline Quality of romantic rela & ships & & & & & & & & & 1.00 \\
\hline
\end{tabular}

$* p<.05$.

psychological pressure, $16(22.5 \%)$ reported substancerelated coercion, $11(15.5 \%)$ reported external psychological manipulation, and $19(26.8 \%)$ reported violent coercion by the perpetrator. Again, these classifications represent the most severe type of coercion a woman reported, since many women reported multiple experiences of sexual victimization: 37 reported one type, 22 reported two types, 10 reported three types, and 2 reported all four types of victimization experiences. The mean numbers of unwanted sexual experiences reported by the four category types were: internal psychological pressure $=1.00$, substance-related coercion $=1.53$, external psychological manipulation $=2.30$, and violent coercion $=2.37$. A regression including dummy variables and a multi-parameter hypothesis test was conducted to compare the number of different kinds of coercion experienced by women in the four coercion categories. This analysis indicated that significant differences existed between all combinations of groups except the external psychological manipulation group and the violent coercion group $\left(\mathrm{R}^{2}=.52, p<.001\right)$.

Information on unwanted sexual intercourse and the circumstances surrounding it were combined to create an overall victimization status for each woman. Categories included: never victimized ( $n=156,68.7 \%)$, violently coerced to have sex (i.e., coerced by the threat or actual use of violence, $n=19,8.4 \%$ ), and nonviolently coerced to have sex (i.e., had sex because of internal psychological pressure, substance-related coercion, or external psychological manipulation, $n=52,22.9 \%$ ). Ten women who did not respond to the initial question on sexual victimization were excluded from analysis.

\section{Preliminary Analyses}

The intercorrelations among the young adult measures of psychosocial adjustment are provided in Table 1. The correlation coefficients ranged in absolute value from $r=.10$ to $r=.67$, (median $r=.33$ ), suggesting some degree of overlap among outcome variables, particularly those reflecting negative affect (emotional tone, anger, and depression) and self-perceptions (self-esteem and body image). The two adolescent adjustment variables were also strongly intercorrelated $(r=.72)$.
Each of the adolescent adjustment variables was significantly associated with most of the young adult adjustment indicators. Grade 9 self-esteem was significantly correlated with all 10 outcome variables (r's ranged from -.14 to .34) and Grade 9 emotional tone was significantly associated with 8 of the outcome variables (r's ranged from -.24 to .29 ).

\section{Relation of Violent and Nonviolent Victimization to Psychosocial Adjustment}

Multiple regression was used to examine the effects of sexual victimization on each young adult adjustment indicator, controlling for adolescent adjustment. Four women who did not have adolescent data were excluded from the regression models; this included 2 women from the internal psychological pressure group, 1 woman from the substance-related coercion group, and 1 women from the external psychological manipulation group.

Table 2. Means of Outcome Variables by Victimization Status

\begin{tabular}{lccc}
\hline & $\begin{array}{c}\text { Never } \\
\text { Victimized } \\
n=156\end{array}$ & $\begin{array}{c}\text { Nonviolent } \\
\text { Coercion } \\
n=48\end{array}$ & $\begin{array}{c}\text { Violent } \\
\text { Coercion } \\
n=19\end{array}$ \\
\hline Emotional tone & 3.84 & 3.92 & 3.32 \\
Depression & $(0.8)$ & $(0.8)$ & $(0.9)$ \\
& 1.91 & 2.02 & 2.14 \\
Anger & $(0.4)$ & $(0.5)$ & $(0.5)$ \\
& 3.20 & 3.21 & 3.67 \\
Self-esteem & $(0.9)$ & $(0.9)$ & $(1.0)$ \\
& 3.29 & 3.28 & 2.83 \\
Body image & $(0.5)$ & $(0.6)$ & $(0.6)$ \\
& 3.78 & 3.69 & 3.28 \\
Assertiveness & $(0.8)$ & $(0.7)$ & $(0.8)$ \\
Intimacy competence & 3.05 & 2.99 & 2.75 \\
& $(0.6)$ & $(0.6)$ & $(0.7)$ \\
Sexual esteem & 2.91 & 2.81 & 2.80 \\
& $(0.8)$ & $(0.8)$ & $(1.0)$ \\
Sexual depression & 5.72 & 5.47 & 4.91 \\
& $(1.2)$ & $(1.3)$ & $(1.2)$ \\
Quality of romantic relationship & 2.44 & 3.02 & 2.95 \\
& $(1.6)$ & $(1.6)$ & $(1.6)$ \\
& 6.18 & 5.81 & 5.45 \\
& $(0.9)$ & $(1.2)$ & $(1.4)$ \\
\hline
\end{tabular}

Note: Standard deviations are noted in parentheses. Means of young adult outcome measures. 
Table 3. Parameter Estimates and Associated Standard Errors for Models Relating Adjustment and Victimization Status

\begin{tabular}{|c|c|c|c|c|c|}
\hline Model: Dependent variable & F-value & $\mathrm{R}^{2}$ & Parameter Estimate & Standard Error & $\mathrm{p}$-value \\
\hline Model: Young adult emotional tone & $6.47 *$ & .08 & & & .0023 \\
\hline Emotional tone: Grade 9 & & & $0.20 *$ & .06 & .0016 \\
\hline Violent coercion & & & $-0.50 *$ & .19 & .0095 \\
\hline Nonviolent coercion & & & 0.06 & .13 & \\
\hline Violent vs. nonviolent coercion & $6.83 * \mathrm{a}$ & & & & .0096 \\
\hline Model: Young adult depression & $5.79 *$ & .08 & & & .0008 \\
\hline Emotional tone: Grade 9 & & & $-0.10^{*}$ & .03 & .0025 \\
\hline Violent coercion & & & $0.22 *$ & .10 & .0303 \\
\hline Nonviolent coercion & & & $0.12+$ & .07 & \\
\hline Violent vs. nonviolent coercion & 0.74 & & & & \\
\hline Model: Young adult self-esteem & $15.18^{*}$ & .18 & & & .0001 \\
\hline Self-esteem: Grade 9 & & & $0.36^{*}$ & .07 & .0001 \\
\hline Violent coercion & & & $-0.41 *$ & .12 & .0007 \\
\hline Nonviolent coercion & & & -0.00 & .08 & \\
\hline Violent vs. nonviolent coercion & $9.53 *$ & & & & .0003 \\
\hline Model: Young adult body image & $5.19 *$ & .07 & & & .0018 \\
\hline Self-esteem: Grade 9 & & & $0.31 *$ & .11 & .0041 \\
\hline Violent coercion & & & $-0.44 *$ & .19 & .0219 \\
\hline Nonviolent coercion & & & -0.07 & .13 & \\
\hline Violent vs. nonviolent coercion & $3.00+$ & & & & \\
\hline Model: Young adult sexual-esteem & $4.19 *$ & .06 & & & .0066 \\
\hline Self-esteem: Grade 9 & & & $0.35 *$ & .16 & .0357 \\
\hline Violent coercion & & & $-0.73^{*}$ & .30 & .0143 \\
\hline Nonviolent coercion & & & -0.22 & .20 & \\
\hline Violent vs. nonviolent coercion & 2.49 & & & & \\
\hline Model: Young adult sexual-depression & $4.86^{*}$ & .07 & & & .0028 \\
\hline Emotional tone: Grade 9 & & & $-0.35^{*}$ & .13 & .0059 \\
\hline Violent coercion & & & 0.47 & .38 & \\
\hline Nonviolent coercion & & & $0.64 *$ & .26 & .0160 \\
\hline Violent vs. nonviolent coercion & 0.15 & & & & \\
\hline Model: Young adult quality of romantic relationship & $5.45^{*}$ & .09 & & & .0013 \\
\hline Self-esteem: Grade 9 & & & $0.40^{*}$ & .15 & .0075 \\
\hline Violent coercion & & & $-0.65^{*}$ & .28 & .0217 \\
\hline Nonviolent coercion & & & $-0.34+$ & .19 & \\
\hline Violent vs. nonviolent coercion & 0.99 & & & & \\
\hline
\end{tabular}

Note. Parameter estimates controlled for Grade 9 adjustment.

${ }^{a}$ A partial F-Statistic from the Multi Parameter Hypothesis Test.

$* p<.05 .+p<.10$.

Grade 9 self-esteem and Grade 9 emotional tone were the best adolescent adjustment measures available. Although they were not optimal control variables for many of the adjustment indicators, they permitted at least a partial control for prior adjustment. Thus, one or the other was included in each regression analysis. Because the measures were highly intercorrelated, it would be inappropriate to include both as controls in the same analysis. As an initial step, adolescent (9th Grade) emotional tone and self-esteem were examined separately in simple regression analyses predicting each of the young adult outcomes. If either proved significant, it was retained as a control variable in subsequent analyses of that outcome. If both were significant, the one that was more strongly related to the outcome was selected as the control variable.

For the regression analyses, the categorical variable of victimization status was recoded into dummy variables. The dummy variables for violently coerced and nonviolently coerced were included in the models, with never victimized as the reference group. One less than the total number of dummy variables were included in each model to avoid collinearity among the independent variables (Hardy, 1993). In addition, the violently coerced and nonviolently coerced groups were compared to each other using a multi-parameter hypothesis test. This joint hypothesis test can be used to test multiple group comparisons within one regression model without introducing additional independent variables (SAS Institute, 1990). Means and standard deviations for the three victimization status groups are in Table 2. The final regression models and the multi-parameter tests are shown in Table 3. Only results for outcomes with significant models are presented.

Emotional tone. The model used to predict young adult emotional tone included Grade 9 emotional tone and dummy variables for violent and nonviolent coercion. Grade 9 emotional tone and violent sexual coercion significantly predicted young adult emotional tone, with violently coerced women $(M=3.32)$ reporting lower emotional tone than the never victimized group $(M=3.84)$. Additionally, the nonviolent and violent coercion groups were significantly different, with the violently coerced group having lower emotional tone than the nonviolent 
coercion group $(M=3.92)$. Thus, violent coercion was associated with worse emotional tone than either no victimization or nonviolent coercion.

Depression. The model used to predict young adult depression included Grade 9 emotional tone along with violent and nonviolent sexual coercion. Grade 9 emotional tone and violent coercion significantly predicted young adult depression. The positive relationship between violent coercion and depression indicated that the violently coerced group $(M=2.14)$ reported greater depression than the never victimized group $(M=1.91)$.

Self-esteem. The model used to predict young adult selfesteem included Grade 9 self-esteem and dummy variables for violent and nonviolent coercion. Grade 9 self-esteem and violent coercion significantly predicted young adult selfesteem; that is, the violently coerced group $(M=2.83)$ had lower adult self-esteem than the never victimized group ( $M$ $=3.29$ ), even with prior self-esteem controlled. Additionally, the violently coerced group had significantly lower selfesteem than the nonviolently coerced group $(M=3.28)$.

Body image. The model used to predict young adult body image included Grade 9 self-esteem and dummy variables for violent and nonviolent coercion. Grade 9 selfesteem and violent coercion each significantly predicted young adult body image. The relation between violent coercion and body image was negative, indicating that the violently coerced group $(M=3.28)$ had lower body image than the never victimized group $(M=3.78)$.

Sexual esteem. Grade 9 self-esteem, violent coercion, and nonviolent coercion were used to predict young adult sexual esteem. Both Grade 9 self-esteem and violent coercion significantly predicted young adult sexual esteem. The relation of violent coercion to sexual esteem was negative, indicating that the violently coerced group ( $M=$ 4.91) had lower sexual esteem than the never victimized group $(M=5.72)$.

Sexual depression. The model used to predict young adult sexual depression included Grade 9 emotional tone and dummy variables for violent and nonviolent coercion. Grade 9 emotional tone and coerced sex each significantly predicted young adult sexual depression. The positive relation between nonviolent coercion and sexual depression indicated that the nonviolent coercion group $(M=3.02)$ had higher sexual depression than the never victimized group $(M=2.44)$.

Quality of current romantic relationship. The model used to predict the quality of romantic relationships included Grade 9 self-esteem and dummy variables for violent and nonviolent coercion. Grade 9 self-esteem and violent coercion significantly predicted young adult quality of romantic relationship. The negative association between violent coercion and relationship quality indicated that the violently coerced group $(M=5.45)$ had lower quality relationships than the never victimized group $(M=$ 6.18). According to this model, violent coercion predicted young adult relationship quality, controlling for adolescent reports of self-esteem.

To summarize, these analyses revealed numerous effects of sexual victimization, especially victimization resulting from violent coercion. Violent coercion was associated with poorer functioning in the areas of emotional tone, depression, self-esteem, body image, sexual esteem, and quality of romantic relationships, whereas nonviolent coercion was associated with greater sexual depression.

Table 4. Means of Young Adult Outcomes by Type of Sexual Victimization Experience

\begin{tabular}{|c|c|c|c|c|}
\hline Measure & $\begin{array}{c}\text { Internal } \\
\text { Psychological } \\
\text { Pressure } \\
n=23\end{array}$ & $\begin{array}{c}\text { Substance } \\
\text { Related } \\
\text { Coercion } \\
n=15\end{array}$ & $\begin{array}{c}\text { External } \\
\text { Psychological } \\
\text { Manipulation } \\
n=10\end{array}$ & $\begin{array}{c}\text { Violent } \\
\text { Coercion } \\
n=19\end{array}$ \\
\hline Emotional tone & $\begin{array}{c}3.89 \\
(0.6)\end{array}$ & $\begin{array}{r}4.33 \\
(0.8)\end{array}$ & $\begin{array}{r}3.39 \\
(0.6)\end{array}$ & 3.32 \\
\hline Depression & $\begin{array}{c}2.08 \\
(0.5)\end{array}$ & $\begin{array}{l}1.86 \\
(0.5)\end{array}$ & $\begin{array}{c}2.12 \\
(0.5)\end{array}$ & $\begin{array}{c}2.14 \\
(0.5)\end{array}$ \\
\hline Anger & $\begin{array}{c}3.34 \\
(0.8)\end{array}$ & $\begin{array}{r}2.80 \\
(1.2)\end{array}$ & $\begin{array}{c}3.51 \\
(0.5)\end{array}$ & $\begin{array}{r}3.67 \\
(1.0)\end{array}$ \\
\hline Self-esteem & $\begin{array}{c}3.33 \\
(0.5)\end{array}$ & $\begin{array}{r}3.54 \\
(0.5)\end{array}$ & $\begin{array}{r}2.79 \\
(0.5)\end{array}$ & $\begin{array}{c}2.83 \\
(0.6)\end{array}$ \\
\hline Body Image & $\begin{array}{c}3.78 \\
(0.6)\end{array}$ & $\begin{array}{c}3.83 \\
(0.9)\end{array}$ & $\begin{array}{r}3.27 \\
(0.3)\end{array}$ & $\begin{array}{c}3.28 \\
(0.8)\end{array}$ \\
\hline Assertiveness & $\begin{array}{r}3.05 \\
(0.7)\end{array}$ & $\begin{array}{r}3.17 \\
(0.6)\end{array}$ & $\begin{array}{c}2.60 \\
(0.4)\end{array}$ & $\begin{array}{c}2.75 \\
(0.7)\end{array}$ \\
\hline Intimacy competence & $\begin{array}{c}3.86 \\
(0.9)\end{array}$ & $\begin{array}{c}2.96 \\
(0.6)\end{array}$ & $\begin{array}{c}2.44 \\
(0.9)\end{array}$ & $\begin{array}{r}2.80 \\
(1.0)\end{array}$ \\
\hline Sexual esteem & $\begin{array}{c}5.20 \\
(1.0)\end{array}$ & $\begin{array}{c}6.04 \\
(1.6)\end{array}$ & $\begin{array}{c}5.23 \\
(1.4)\end{array}$ & $\begin{array}{r}4.91 \\
(1.2)\end{array}$ \\
\hline Sexual depression & $\begin{array}{c}3.24 \\
(1.6)\end{array}$ & $\begin{array}{c}2.50 \\
(1.5)\end{array}$ & $\begin{array}{c}3.30 \\
(1.7)\end{array}$ & $\begin{array}{c}2.95 \\
(1.6)\end{array}$ \\
\hline Quality of romantic relationship & $\begin{array}{r}5.97 \\
(1.2)\end{array}$ & $\begin{array}{c}5.89 \\
(1.1)\end{array}$ & $\begin{array}{c}5.30 \\
(1.1)\end{array}$ & $\begin{array}{r}5.45 \\
(1.4)\end{array}$ \\
\hline
\end{tabular}

Note. Standard deviations are noted in parentheses. Means of young adult outcome measures. 
Furthermore, women who reported violent coercion showed poorer emotional tone and self-esteem than women who reported only nonviolent forms of coercion.

\section{Type of Coercion and Subsequent Adjustment}

A similar analysis strategy was used to determine the relative impact of different types of sexual coercion on women's adjustment. First, adolescent emotional tone and self-esteem were examined in simple regression models, with the most highly predictive variable retained in subsequent analyses. Next, the adjustment control variable and dummy variables representing substance-related coercion, external psychological manipulation, and violent coercion (with internal psychological pressure as the reference group), were included in models predicting young adult outcomes. Multi-parameter hypothesis tests were employed to compare the remaining three groups with each other. Means and standard deviations of the outcome variables by type of victimization appear in Table 4. Results of significant regression models are summarized in Table 5.

Emotional tone. The model used to predict young adult emotional tone included Grade 9 emotional tone, substance-related coercion, external psychological manipulation, and violent coercion. Violent coercion significantly predicted young adult emotional tone. The latter effect was negative, indicating that women who had experienced the threat or use of physical violence $(M=3.22)$ reported poorer emotional tone than those who had experienced only internal psychological pressure to have sex $(M=$ 3.89). In addition, women who had experienced substance-

Table 5. Parameter Estimates and Associated Standard Errors for Models Relating Adjustment and Type of Sexual Victimization

\begin{tabular}{|c|c|c|c|c|c|}
\hline Model: Dependent variable & F-value & $\mathrm{R}^{2}$ & Parameter Estimate & Standard Error & $p$-value \\
\hline Model: Young adult emotional tone & $5.39 *$ & .26 & & & .0009 \\
\hline Emotional tone: Grade 9 & & & $0.22+$ & .12 & \\
\hline Substance related coercion & & & $0.43+$ & .25 & \\
\hline External psychological manipulation & & & -0.34 & .30 & \\
\hline Violent coercion & & & $-0.49 *$ & .24 & .0446 \\
\hline Substance vs. external psychological & $5.76^{* a}$ & & & & .0194 \\
\hline Substance vs. violent coercion & $11.95^{*}$ & & & & .0010 \\
\hline External psychological vs. violent coercion & 0.25 & & & & \\
\hline Model: Young adult anger & $3.15^{*}$ & .17 & & & .0202 \\
\hline Emotional tone: Grade 9 & & & $-0.29 *$ & .14 & .0421 \\
\hline Substance related coercion & & & $-0.53+$ & .30 & \\
\hline External psychological manipulation & & & -0.04 & .35 & \\
\hline Violent coercion & & & 0.21 & .28 & \\
\hline Substance vs. external psychological & 1.67 & & & & \\
\hline Substance vs. violent coercion & $5.50 *$ & & & & .0222 \\
\hline External psychological vs. violent coercion & 0.49 & & & & \\
\hline Model: Young adult self-esteem & $8.93 *$ & .37 & & & .0001 \\
\hline Self-esteem: Grade 9 & & & $0.42 *$ & .13 & .0025 \\
\hline Substance related coercion & & & 0.20 & .16 & \\
\hline External psychological manipulation & & & $-0.43 *$ & .19 & .0277 \\
\hline Violent coercion & & & $-0.43^{*}$ & .16 & .0075 \\
\hline Substance vs. external psychological & $9.56^{*}$ & & & & .0030 \\
\hline Substance vs. violent coercion & $13.44 *$ & & & & .0005 \\
\hline External psychological vs. violent coercion & 0.00 & & & & \\
\hline Model: Young adult assertiveness & $2.41+$ & .13 & & & \\
\hline Self-esteem: Grade 9 & & & 0.23 & .16 & \\
\hline Substance related coercion & & & 0.11 & .20 & \\
\hline External psychological manipulation & & & $-0.39+$ & .23 & \\
\hline Violent coercion & & & -0.26 & .19 & \\
\hline Substance vs. external psychological & $4.00^{*}$ & & & & .0500 \\
\hline Substance vs. violent coercion & $3.02+$ & & & & \\
\hline External psychological vs. violent coercion & 0.32 & & & & \\
\hline Model: Young Adult Sexual-esteem & 1.77 & .10 & & & \\
\hline Self-esteem: Grade 9 & & & 0.12 & .35 & \\
\hline Substance related coercion & & & $0.84+$ & .43 & \\
\hline External psychological manipulation & & & $0.06+$ & .49 & \\
\hline Violent coercion & & & -0.27 & .40 & \\
\hline Substance vs. external psychological & 2.14 & & & & \\
\hline Substance vs. violent coercion & $6.13 *$ & & & & .0160 \\
\hline External psychological vs. violent coercion & 0.44 & & & & \\
\hline
\end{tabular}

Note. Parameter estimates controlled for Grade 9 adjustment.

${ }^{\text {a }}$ A partial F-Statistic from the Multi Parameter Hypothesis Test.

$* p<.05 .+p<.10$. 
related coercion $(M=4.33)$ reported higher emotional tone than women who had experienced external psychological manipulation $(M=3.39)$ or physical violence $(M=3.22)$.

Anger. The model for young adult anger included Grade 9 emotional tone and the three coercion dummy variables. Grade 9 emotional tone predicted young adult anger, but the three dummy variables were not significant, indicating that the women in these groups did not differ from those who had experienced only internal psychological pressure. However, the multi-parameter hypothesis test revealed a group difference between the substance-related coercion group and the violent coercion group. Women who experienced violent coercion $(M=3.67)$ reported higher levels of anger than women who experienced substance-related coercion $(M=2.80)$.

Self-esteem. The model used to predict young adult selfesteem included Grade 9 self-esteem and dummy variables for substance-related coercion, external psychological manipulation, and violent coercion. Three of the independent variables, Grade 9 self-esteem, external psychological manipulation, and violent coercion significantly predicted young adult self-esteem. Specifically, women who experienced either external psychological manipulation $(M=$ $2.79)$ or violent coercion $(M=2.83)$ reported lower selfesteem than women who only experienced internal psychological pressure $(M=3.33)$. Additionally, women who experienced violent coercion or external psychological manipulation reported lower self-esteem than those who experienced substance-related coercion $(M=3.54)$.

Assertiveness. The model used to predict young adult assertiveness included Grade 9 self-esteem and dummy variables for substance-related coercion, external psychological manipulation, and violent coercion. A significant difference was found between the substance-related coercion and external psychological manipulation groups, indicating that women in the substance-related coercion group $(M=3.17)$ had higher levels of assertiveness than women who had experienced external psychological manipulation $(M=2.60)$.

Sexual esteem. The model used to predict young adult sexual esteem included Grade 9 self-esteem and dummy variables for substance-related coercion, external psychological manipulation, and violent coercion. A significant difference was found between the substance-related coercion and violent coercion groups, indicating that women in the substance-related coercion group $(M=6.04)$ had higher sexual esteem than women who had experienced physical violence $(M=4.91)$.

In summary, these analyses revealed differences in the adjustment levels of women who experienced different types of sexual coercion. Compared to those who experienced only internal psychological pressure, women who were violently coerced reported poorer emotional tone and self-esteem, whereas women who were psychologically manipulated reported poorer self-esteem. Compared to those who reported substance-related coercion, women who reported violent coercion had lower emotional tone, self-esteem, and sexual esteem along with higher levels of anger; women who experienced external psychological manipulation reported lower emotional tone, lower selfesteem, and lower assertiveness.

\section{DISCUSSION}

The present study provides strong support for the notion that sexual victimization has implications for how a woman subsequently feels about herself and her life. The finding that women who reported unwanted sexual experiences exhibited poorer psychological and social/relational adjustment reinforces the results of prior studies that have linked sexual victimization to lower self-esteem (Murphy et al., 1988; Zweig et al., 1997), increased depression and anger (Erickson \& Rapkin, 1991; Siegel et al., 1990; Zweig et al., 1997), and problems with romantic relationships (Jehu \& Gazan, 1983). However, in contrast to earlier studies, the present study included controls for adolescent psychological adjustment, yielding stronger evidence for the causal role of sexual victimization in producing negative outcomes.

The present findings extend the range of psychological dimensions that have been linked to sexual victimization: Body-image, sexual esteem, and sexual depression all appeared to be affected by sexual coercion. These findings also suggest avenues for future research. For example, some previous studies have linked sexual victimization to weight problems (Erickson \& Rapkin, 1991) and eating disorders (Kearney-Cooke, 1988). The present findings suggest the need to examine the possible mediating role of poor body image in these relationships. Similarly, the finding of lower sexual esteem and higher sexual depression among coerced women parallel the relationships that have been previously identified between victimization and reduced sexual interest and satisfaction (Siegel et al., 1990; Zweig, 1995). At the same time, it should be noted that several adjustment indicators were strongly intercorrelated (e.g., self-esteem, emotional tone, and body image). The evidence of shared variance between these indicators suggests that they may not all represent truly distinct outcomes.

Results of the initial regressions, which compared women who were never victimized with those who were violently coerced and those who experienced some nonviolent form of coercion, raise an important caveat. With only one exception, all of the significant differences between victimized and nonvictimized women involved women who had been violently coerced. Moreover, in two instances (for self-esteem and emotional tone) women who were violently coerced exhibited significantly lower wellbeing than women who had experienced nonviolent forms of coercion. These results suggest that violent coercion has more pervasive and powerful effects on women's psychosocial adjustment than coercion that does not involve violence or the threat of violence. Given this pattern, it would seem critical to distinguish violent coercion from other forms of sexual coercion in future research. 
Prior studies have yielded inconsistent findings about the relative impact of violent and nonviolent victimization on women's adjustment. Consonant with the present results, Siegel et al. (1990) reported that women who were physically threatened during their sexual assault experience were more likely to report depression and anger problems than women who were pressured by persuasion. In contrast, Zweig and colleagues (1997) reported that women who were pressured to have sex had higher depression and anger scores than women who were forced to have sex. Finally, Mynatt and Allgeier ( 1990) reported that women who were coerced by psychological means reported lower levels of adjustment than women coerced by physical means. However, women who suffered greater physical injury also reported lower levels of adjustment than women who did not suffer physical injury. Thus, the severity of the negative consequences following violent coercion (and possibly the relative impact of violent coercion and psychological manipulation) may depend on whether physical injury occurred.

The inconsistent findings may also reflect differences in measures. For example, Zweig et al. (1997) asked participants if they had experienced sexual victimization using yes/no questions about rape, sexual abuse, and sexual assault, and a frequency count of intercourse experiences in response to pressure. It is not clear what kinds of coercion (violent or nonviolent) actually occurred during these victimizing episodes. In contrast, the study by Siegel et al. (1990) and the present study used more specific questions to assess the nature of the experience. For example, participants reported information such as whether or not the perpetrator threatened them with a weapon, held them down, or used verbal humiliation. Notably, the two studies using more specific questions found similar patterns, despite the different samples studied (rural in the present study; urban in the Siegel et al. study).

The second set of regressions, which provided more detailed information on the effects of different kinds of sexual coercion, revealed that violent coercion is not the only type of sexual coercion with detrimental psychological effects. These regressions compared the effects of internal psychological pressure, substance-related coercion, external psychological manipulation, and violent coercion to determine which kinds of experiences were more debilitating. The results of these analyses indicate that where significant differences emerge, violent coercion and psychological manipulation are both more debilitating than either internal pressure or substance-related coercion. Compared to the latter groups, violently coerced women showed poorer functioning in six instances and psychologically manipulated women showed poorer functioning in four instances, indicating that the effects of violent coercion may be somewhat more pervasive. However, in no case did the adjustment of violently coerced women differ significantly from that of psychologically manipulated women. Thus, one form of nonviolent coercion (i.e., external psychological manipulation) appears to be as psycho- logically debilitating as violent coercion. This indicates a need to distinguish both violently coerced and psychologically manipulated women in future research. Moreover, these groups of women may need to be targeted for intervention, since they seem to suffer the most in terms of psychological well-being.

Why might women who are violently coerced and women who are psychologically manipulated be similarly affected psychologically and suffer more adverse consequences than women who experience only internal psychological pressure or substance-related coercion? One explanation is that this is an artifact of the way we constructed our categories for types of coercion. ${ }^{5}$ Specifically, we classified women based on the most severe form of coercion experienced, which meant that women in the more severe categories could potentially have experienced more forms of coercion. If the number of types of coercive experiences was the critical factor producing the findings, we would have expected violently coerced and psychologically manipulated women to have experienced significantly more different kinds of coercion than the other two groups. Although this pattern was obtained, additional findings refute that explanation-the substance-related coercion group also experienced significantly more types of coercion than the internal psychological pressure group; however, they did not experience worse outcomes. Thus, although we cannot entirely rule out this explanation, it seems unlikely.

A second explanation involves self-blame. Self-blame has been found to mediate the relationship between victimization and negative psychological outcomes, with higher self-blame being associated with poorer outcomes (Meyer \& Taylor, 1986; Wyatt, Notgrass, \& Newcomb, 1990). Moreover, prior research has shown that women who are raped may feel they played a role in their victimization. Two types of self-blame have been documented for women who experience rape: (a) Characterological selfblame is when a woman feels responsible for her victimization due to stable aspects of herself, and (b) behavioral self-blame is when a woman feels responsible for her victimization due to her own behaviors (Frazier \& Schauben, 1994; Meyer \& Taylor, 1986). These two types of selfblame, one that focuses on the woman's identity and one that focuses on her behaviors, may be directly related to later problems with self-perceptions and moods. It is not known whether women who have been subjected to other forms of unwanted sexual activity experience similar levels or types of blame, but it is possible that self-blame is higher among those who have been violently coerced or psychologically manipulated to have sex than among those who have experienced only internal psychological pressure or substance-related coercion. Women who experience pressure from themselves or have experiences while intoxicated may not feel that they played a role in a vic-

\footnotetext{
${ }^{5}$ We thank an anonymous reviewer for pointing out this confound.
} 
timizing experience. Examining this possibility could be a fruitful avenue for future studies.

Yet a third explanation relates to the level of humiliation and degradation experienced with different forms of sexual coercion. It seems plausible that women who have unwanted sex because they feel obligated to or want to please their partner (internal psychological pressure) might be able to rationalize the experience in such a way that they do not feel humiliated or degraded. Similarly, a woman who was so intoxicated that she did not know what was happening or did not care if she had sex may be able to reconstruct the event so that the feeling of having been violated and degraded is minimized. In contrast, such reconstruction would seem far more difficult for a woman who recognizes that she was psychologically manipulated (e.g., made to feel worthless until she submitted) or physically forced to have sex. Without the psychological buffer provided by the opportunity to rationalize or reconstruct the event, these women may experience the full impact of their humiliation and powerlessness, with detrimental effects for their psychological well-being. Clearly, this explanation is only speculative at present and requires examination in future studies.

The findings also offer additional fuel for the debate over what constitutes victimization. We chose to consider a broad spectrum of unwanted sexual experiences under the rubric of sexual victimization, because we felt it was important to examine empirically whether different kinds of sexual coercion have detrimental effects rather than to assume a priori that certain kinds of unwanted sexual experiences are not debilitating because they do not meet some external criterion for victimization. In this regard our findings were instructive. We learned that violent coercion, which most scholars would agree reflects victimization, was indeed associated with poorer adjustment, but so was psychological manipulation, which does not meet the legal definition of rape and which some scholars might discount as victimization. Equally interesting is the finding that women who experienced substance-related coercion, some instances of which do meet the legal definition of rape, exhibited better psychological adjustment than psychologically manipulated women and were indistinguishable from women who reported only internal psychological pressure. These findings suggest that neither the legal definition of rape nor the criterion of consent are the key factors in predicting the psychological impact of unwanted intercourse.

Regarding definitional issues, it may be instructive to note that differences between victimized (primarily violently coerced) women and nonvictimized women emerged in both psychological and social/relational adjustment, but differences among women experiencing different types of coercion appeared almost exclusively in the psychological domain. This suggests that women's social/relational adjustment may be similarly affected by different kinds of sexually coercive experiences, but that psychological wellbeing is especially vulnerable to coercion that involves either violence or psychological manipulation.
Several limitations need to be considered in interpreting these results. First, the findings are based on a small number of women, somewhat limiting our ability to detect associations between experiences and psychosocial adjustment. Second, because participants were not asked the age at which they first had unwanted sexual experiences, it is possible that some cases of unwanted sexual experience occurred before Grade 9, when the control variables were assessed. It is important to note, however, that this limitation would tend to decrease the chances of finding effects. For example, if sexual victimization occurred prior to Grade 9 and Grade 9 self-esteem was controlled in models predicting young adult self-esteem, we would have controlled for some of the effect of interest. Third, we only had precise adolescent control variables for self-esteem and emotional tone. Future prospective studies should control for adjustment using the same constructs measured both prior to and after victimization experiences. Fourth, the intercorrelations between some of the adjustment indicators were high, suggesting shared variance. This was particularly true for psychological adjustment measures. Thus, we cannot assume that all the findings reflect distinct relationships. Future studies might focus on measures of adjustment that are less closely related. Finally, the four types of sexual coercion do not represent mutually-exclusive categories. Many women who experienced the more severe types of sexual victimization, such as violent coercion or external psychological manipulation, also experienced other forms of unwanted sexual experiences. Our analysis of the number of types of coercion experienced by women in the four groups suggested that the number of types of coercion could not explain the pattern of differences in psychological well-being between women experiencing different kinds of coercion. Still, we cannot fully disentangle the effects of multiple experiences from the type of victimization experienced.

Nonetheless, the current study makes two important contributions to the existing literature. First, owing to the inclusion of controls for prior adjustment, a stronger case can be made that sexual victimization is a harmful experience for women, with lasting effects on their psychological well-being and social adjustment. Second, sexual victimization that involves coercion through violence or psychological manipulation appears to be more detrimental than other types of unwanted experiences.

\section{REFERENCES}

Bachman, R., \& Saltzman, L. E. (1995). Violence against women: Estimates from the redesigned survey. Published Report. United States Department of Justice.

Baltes, P. B., Reese, H. W., \& Nesselroade, J. R. (1977). Life-span developmental psychology: Introduction to research methods. Hillsdale, $\mathrm{NJ}$ : Lawrence Erlbaum Associates.

Braiker, H. B., \& Kelley, H. H. (1979). Conflict in the development of close relationships. In R. L. Burgess \& T. L. Huston (Eds.), Social exchange in developing relationships (pp. 135-168). New York: Academic Press.

Christopher, F. S. (1988). An initial investigation into a continuum of premarital sexual pressure. The Journal of Sex Research, 25, 255-266.

Crockett, L. J., Bingham, C. R., Chopak, J. S., \& Vicary, J. R. (1996). Timing of first sexual intercourse: The role of social control, social learning, and problem behavior. Journal of Youth and Adolescence, 25, 89-111. 
Derogatis, L. R., \& Melisaratos, N. (1983). The brief symptom inventory: An introductory report. Psychological Medicine, 13, 595-605.

Erickson, P. I., \& Rapkin, A. J. (1991). Unwanted sexual experiences among middle and high school youth. Journal of Adolescent Health, 12, 319-325.

Frazier, P., \& Schauben, L. (1994). Causal attributions and recovery from rape and other stressful life events. Journal of Social and Clinical Psychology, 13, 1-14.

George, L. K., Winfield, I., \& Blazer, D. G. (1992). Sociocultural factors in sexual assault: Comparison of two representative samples of women. Journal of Social Issues, 48, 105-125.

Hardy, M. (1993). Regression with dummy variables. Newbury Park, CA: Sage Publications.

Harlow, C. W. (1991). Female victims of violent crime. Published Report. United States Department of Justice.

Himelein, M. J. (1995). Risk factors for sexual victimization in dating: A longitudinal study of college women. Psychology of Women Quarterly, 19, $31-48$.

Himelein, M. J., Vogel, R. E., \& Wachowiak, D. G. (1994). Nonconsensual sexual experiences in precollege women: Prevalence and risk factors. Journal of Counseling \& Development, 72, 411- 415.

Jehu, D., \& Gazan, M. (1983). Psychosocial adjustment of women who were sexually victimized in childhood or adolescence. Canadian Journal of Community of Mental Health, 2, 71-82.

Kandel, D. B., \& Davies, M. (1986). Adult sequelae of adolescent depression symptoms. Archives of General Psychiatry, 43, 255-262.

Kearney-Cooke, A. (1988). Group treatment of sexual abuse among women with eating disorders. Women \& Therapy, 7, 5-21.

Kilpatrick, D. G., Best, C. L., Saunders, B. E., \& Veronen, L. J. (1988). Rape in marriage and in dating relationships: How bad is it for mental health? In R. A. Prentky \& V. L. Quinsey (Eds.), Annals of the New York Academy of Sciences: Vol. 528. Human sexual aggression: Current perspectives (pp. 335-344). New York: The New York Academy of Sciences.

Koss, M. P. (1985). The hidden rape victim: Personality, attitudinal, and situational characteristics. Psychology of Women Quarterly, 9, 193-212.

Koss, M. P. (1993). Detecting the scope of rape: A review of prevalence research methods. Journal of Interpersonal Violence, 8, 198-222.

Koss, M. P., Gidycz, C. A., \& Wisniewski, N. (1987). The scope of rape: Incidence and prevalence of sexual aggression and victimization in a national sample of higher education students. Journal of Consulting and Clinical Psychology, 55, 162-170.

Koss, M. P., \& Oros, C. J. (1982). Sexual experiences survey: A research instrument investigating sexual aggression and victimization. Journal of Consulting and Clinical Psychology, 50, 455-457.

Laumann, E. O., Gagnon, J. H., Michael, R. T., \& Michaels, S. (1994). The social organization of sexuality. Chicago: The University of Chicago Press.

Levenson, R. W., \& Gottman, J. M. (1978). Toward the assessment of social competence. Journal of Counseling and Clinical Psychology, 46, 453-462.

Mackey, T., Sereika, S. M., Weissfeld, L. A., Hacker, S. S., Zender, J. F., \& Heard, S. L. (1992). Factors associated with long-term depressive symptoms of sexual assault victims. Archives of Psychiatric Nursing, 6, 10-25.

McCrae, R. R., \& Costa, P. T. (1989). Rotation to maximize the construct validity of factors in the NEO Personality Inventory. Multivariate Behavioral Research, 24, 107-124.

Meyer, C. B., \& Taylor, S. E. (1986). Adjustment to rape. Journal of Personality and Social Psychology, 50, 1226-1234.
Miller, B. C., Monson, B. H., \& Norton, M. C. (1995). The effects of forced sexual intercourse on white female adolescents. Child Abuse \& Neglect, 19, 1289-1301.

Muehlenhard, C. L., \& Cook, S. W. (1988). Men's self-reports of unwanted sexual activity. The Journal of Sex Research, 24, 58-72.

Muehlenhard, C. L., Goggins, M. F., Jones, J. M., \& Satterfield, A. T. (1991). Sexual violence and coercion in close relationships. In K. McKinney \& S. Sprecher (Eds.), Sexuality in close relationships (pp. 155-175). Hillsdale, NJ: Lawrence Erlbaum Associates.

Murphy, S. M., Amick-McMullan, A. E., Kilpatrick, D. G., Haskett, M. E., Veronen, L. J., Best, C. L., \& Saunders, B. E. (1988). Rape victims' selfesteem: A longitudinal analysis. Journal of Interpersonal Violence, 3, 355-370.

Mynatt, C. R., \& Allgeier, E. R. (1990). Risk factors, self-attributions, and adjustment problems among victims of sexual coercion. Journal of Applied Social Psychology, 20, 130-153.

O'Sullivan, L. F., \& Allgeier, E. R. (1998). Feigning sexual desire: Consenting to unwanted sexual activity in heterosexual dating relationships. The Journal of Sex Research, 35, 234-243.

Petersen, A. C., Schulenberg, J. E., Abramowitz, R. H., Offer, D., \& Jarcho, H. D. (1984). A self-image questionnaire for young adolescents (SIQYA): Reliability and validity studies. Journal of Youth and Adolescence, 9, 491-506.

Resick, P. A. (1993). The psychological impact of rape. The Journal of Interpersonal Violence, 8, 223-255.

Rosenberg, M. (1965). Society and the adolescent self-image. Princeton, NJ: Princeton University Press.

SAS Institute (1990). SAS/STAT user's guide: Version 6 (4th ed., Vol. 2). Cary, NC: Author.

Siegel, J. M., Golding, J. M., Stein, J. A., Burnam, M. A., \& Sorenson, S. B. (1990). Reactions to sexual activity: A community study. Journal of Interpersonal Violence, 5, 229-246.

Snell, W. E., \& Papini, D. R. (1989). The Sexuality Scale: An instrument to measure sexual-esteem, sexual-depression, and sexual-preoccupation. The Journal of Sex Research, 26, 256-263.

Spanier, G. (1976). Measuring dyadic adjustment: New scales for assessing the quality of marriage and similar dyads. Journal of Marriage and the Family, 38, 15-28.

Vicary, J. R. (1991). Psychological impact of pregnancy on rural adolescents. Final Report for Grant \# APR 000933-01.

Vicary, J. R., Klingaman, L. R., \& Harkness, W. L. (1995). Risk factors associated with date rape and sexual assault of adolescent girls. Journal of Adolescence, 18, 289-306.

Wiehe, V. R., \& Richards, A. L. (1995). Intimate betrayal: Understanding and responding to the trauma of acquaintance rape. Thousand Oaks, CA: Sage Publications.

Wyatt, G. E., Notgrass, C. M., \& Newcomb, M. (1990). Internal and external mediators of women's rape experiences. Psychology of Women Quarterly, 14, 153-176.

Zweig, J. M. (1995). Sexual coercion and well-being in young adulthood: Experiences based on gender and college enrollment. Unpublished master's thesis: The Pennsylvania State University.

Zweig, J. M., Barber, B. L., \& Eccles, J. S. (1997). Sexual coercion and wellbeing in young adulthood: Comparisons by gender and college status. Journal of Interpersonal Violence 12, 291-308.

Manuscript accepted July 25, 1999

\section{APPENDIX A}

\section{Measure of SEXUAL Victimization}

\section{Have you ever had sexual intercourse with someone when you didn't want to?}

\section{No (SKIP TO \#67)}

2. Yes

2. Have you ever had sexual intercourse when you didn't want to because of the following reasons? (Check all that apply.)

1. You were so drunk or stoned that you were unaware of what was going on? 
2. You were so drunk or stoned that you couldn't do anything to stop the other person?

3. You were so drunk or stoned that you didn't care?

4. The other person used physical violence (for instance, slapping, hitting)?

5. The other person held you down or made it so you couldn't leave?

6. The other person threatened you with a weapon?

7. You were afraid the other person would use physical violence (for instance, slapping, hitting)?

8. The other person threatened to end the relationship?

9. The other person made you feel worthless or humiliated until you gave in?

10. You felt obligated.

11. You wanted to please the other person. 